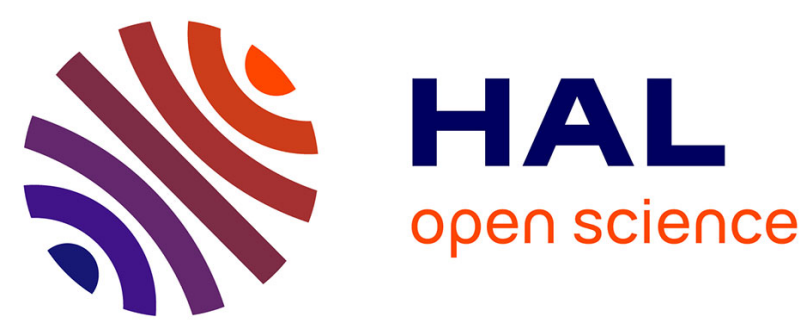

\title{
Combination effect of polyhedral oligomeric silsesquioxane (POSS) and a phosphorus modified PMMA, flammability and thermal stability properties
}

Hossein Vahabi, Laurent Ferry, Claire Longuet, Belkacem Otazaghine, Claire Negrell-Guirao, Ghislain David, José-Marie Lopez-Cuesta

\section{To cite this version:}

Hossein Vahabi, Laurent Ferry, Claire Longuet, Belkacem Otazaghine, Claire Negrell-Guirao, et al.. Combination effect of polyhedral oligomeric silsesquioxane (POSS) and a phosphorus modified PMMA, flammability and thermal stability properties. Materials Chemistry and Physics, 2012, 136, pp.762770. 10.1016/j.matchemphys.2012.07.053 . hal-00728438

\section{HAL Id: hal-00728438 https://hal.science/hal-00728438}

Submitted on 8 Jul 2021

HAL is a multi-disciplinary open access archive for the deposit and dissemination of scientific research documents, whether they are published or not. The documents may come from teaching and research institutions in France or abroad, or from public or private research centers.
L'archive ouverte pluridisciplinaire HAL, est destinée au dépôt et à la diffusion de documents scientifiques de niveau recherche, publiés ou non, émanant des établissements d'enseignement et de recherche français ou étrangers, des laboratoires publics ou privés. 


\title{
Combination effect of polyhedral oligomeric silsesquioxane (POSS) and a phosphorus modified PMMA, flammability and thermal stability properties
}

\author{
H. Vahabi ${ }^{\text {a }}$, L. Ferry ${ }^{\text {a }}$, C. Longuet ${ }^{\mathrm{a}, *}$, B. Otazaghine ${ }^{\text {a }}$, C. Negrell-Guirao ${ }^{\text {b }}$, G. David ${ }^{\text {b }}$, J.-M. Lopez-Cuesta ${ }^{\text {a }}$ \\ ${ }^{a}$ Ecole des Mines d'Alès, Centre CMGD, 6 avenue de Clavières, F-30319 Alès Cedex, France \\ ${ }^{\mathrm{b}}$ Laboratoire d'Ingénierie et Architectures Macromoléculaires (IAM), Ecole Nationale Supérieure de Chimie de Montpellier (ENSCM), 8 rue de l'école normale, \\ 34296 Montpellier Cedex 5, France
}

\section{H I G H L I G H T S}

- Physical incorporation of two types of POSS in two types of polymethacrylate matrices.

- Synthesis of copolymer methacrylate POSS.

- Synergy between phosphorus and silicon (POSS).

- Thermal degradation and fire behavior characterizations.

\begin{abstract}
A B S T R A C T
The influence of two different types of polyhedral oligomeric silsesquioxane (POSS): trisilanolphenylPOSS (Tr.POSS) and methacrylateethyl-POSS (MA.POSS) on thermal degradation and flammability properties of both PMMA and a phosphonated modified PMMA (copo.(MMA-MAPC1) has been investigated using TGA, PCFC and Py-GC/MS. The physical incorporation of MA.POSS in phosphonated modified PMMA (copo.(MMA-MAPC1)) enables to increase thermal stability properties compared to pristine phosphonated polymer due to the interaction between POSS radical sites and phosphorus species formed during thermal degradation. The reactive incorporation of POSS into PMMA was assessed by synthesizing copolymer and terpolymer of MA.POSS with MMA and MAPC1. It has been highlighted that, compared to the physical blends, the introduction of the POSS cage in the polymer chains induces a shift of degradation onset toward high temperature, an increase of the residue amount as well as a decrease of the heat release.
\end{abstract}

\section{Introduction}

Over the past decade, several research works have been devoted to the reduction of flammability of PMMA and several routes have been proposed [1-4]. Recently we reported the chemical incorporation of a phosphonated group into PMMA via copolymerization [5]. The study showed the effectiveness of this method (compared to physical method, blend of PMMA and phosphorus flame retardant) since a significant improvement of flame retardancy of PMMA was achieved. On the other hand, the combination of nanoparticles with traditional flame retardants has emerged recently as a promising way to reduce flammability of polymers [6]. Moreover, the combination of nanoparticles with a flame retardant which is

\footnotetext{
* Corresponding author. Tel.: +3346678 53 45; fax: +3346678 5365 . E-mail address: Claire.Longuet@mines-ales.fr (C. Longuet).
}

chemically attached to polymer has proven to be an attractive and suitable method [7]. Among the nano-dimensional particles, polyhedral oligomeric silsesquioxane (POSS) has attracted much attention in recent years because of its interesting combination of properties $[8,9]$. POSS molecules form a continuous protective solid layer on the surface of polymer during burning and thus enhance its flame resistance $[10,11]$. Moreover, it has been shown by Zheng et al. [12] that POSS improved the thermooxidative stabilities of polymers. Furthermore, POSS can possess different chemical side groups which can facilitate its chemical incorporation into a given polymer via blending [13,14] or copolymerization [15-17].

The current work focuses on the effect of two different POSS (trisilanolphenyl-POSS and methacrylateethyl-POSS (Tr.POSS and MA.POSS)) addition on thermal stability and flammability of both PMMA and a phosphonated modified PMMA (copo.(MMA-MAPC1)). Moreover, the effect of methacrylateethylPOSS in PMMA was investigated through chemical and physical 


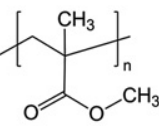

(a)

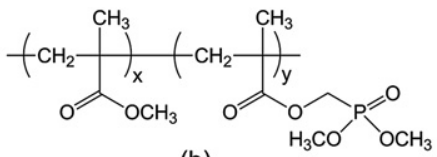

(b)

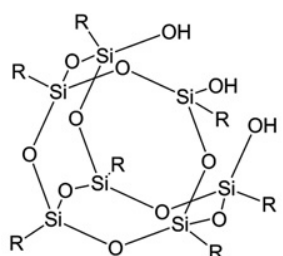

(c) $\mathrm{R}=$ Phenyl

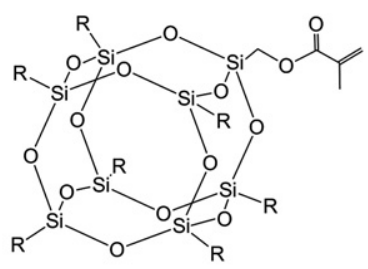

(d) R = Ethyl

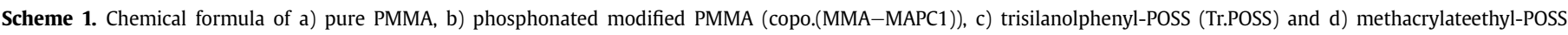
(MA.POSS).

addition routes. To achieve this aim, a copolymer MMA-POSS and a terpolymer (MMA-MAPC1-POSS) were synthesized and compared with PMMA/POSS or copo.(MMA-MAPC1)/POSS physical blends.

\section{Materials and methods}

PMMA and phosphonated modified PMMA (copo. (MMA-MAPC1)) (Scheme $1-a, b)$ were synthesized via radical polymerization method. Their synthesis methods were described in a previous work [5]. Trisilanolphenyl-POSS ${ }^{\circledR}$ (SO1458) (named as Tr.POSS) and methacrylateethyl-POSS ${ }^{\circledR}$ (MA0716) (named as MA.POSS) were used as purchased from Hybrid Plastics (Scheme 1 $-\mathrm{c}, \mathrm{d})$.

Blends of PMMA or phosphonated modified PMMA with POSS (MA.POSS or Tr.POSS) were prepared by solution blending (casting) method using tetrahydrofuran (THF) as solvent. First, PMMA or copo.(MMA-MAPC1) was dissolved in THF at room temperature. The calculated amount of POSS was added into this solution and stirred to obtain uniform dispersion. The mixture was cast onto a Petri dish to allow THF to freely evaporate. The obtained blends were dried in a vacuum oven at $80^{\circ} \mathrm{C}$ prior to characterizations.

The copolymer, copo.(MMA-MA.POSS), was obtained via copolymerization of MMA and MA.POSS. This copolymer was prepared via free radical polymerization technique as shown in Scheme 2. In a two necked flask equipped with a condenser under nitrogen were introduced MMA, MA.POSS (10 wt.\%) and toluene. Then, three molar percent equivalents of initiator 2,2-azo-bis-isobutyronitrile (AIBN) were added to the solution which was stirred and heated at $65{ }^{\circ} \mathrm{C}$ for $15 \mathrm{~h}$ to achieve the polymerization. The solution was then precipitated in methanol and the obtained polymer was dried under vacuum at $80^{\circ} \mathrm{C}$.

${ }^{1} \mathrm{H}$ NMR $\left(\mathrm{CDCl}_{3}, \delta, \mathrm{ppm}\right): 0.55$ (POSS $\left.-\mathbf{C H}_{2}-\mathrm{CH}_{3}\right), 0.86\left(\mathbf{C H}_{3}-\mathrm{C}\right)$, 0.93 (POSS $\left.-\mathrm{CH}_{2}-\mathbf{C H}_{3}\right), \quad 1.74 \quad\left(\mathbf{C H}_{2}-\mathrm{C}\right), 3.53\left(\mathrm{O}-\mathbf{C H}_{3}\right.$ and $\mathrm{O}-\mathbf{C H}_{2}-\mathrm{POSS}$ ).
SEC: $M_{\mathrm{n}}=21,900 \mathrm{~g} \mathrm{~mol}^{-1}, M_{\mathrm{w}} / M_{\mathrm{n}}=3.0$.

The terpolymer, terpo.(MMA-MAPC1-MA.POSS) (Scheme 3), was synthesized using the same method as described above for the copolymer, copo.(MMA-MA.POSS). ${ }^{1} \mathrm{H}$ NMR (DMSO- $d_{6}, \delta, \mathrm{ppm}$ ): 0.63 (POSS $\left.-\mathbf{C H}_{2}-\mathrm{CH}_{3}\right), 0.88\left(\mathbf{C H}_{3}-\mathrm{C}\right), 0.97$ (POSS $\left.-\mathrm{CH}_{2}-\mathbf{C H}_{3}\right), 1.81$ $\left(\mathbf{C H}_{2}-\mathrm{C}\right), 3.56\left(\mathrm{O}-\mathbf{C H}_{3}\right.$ and $\left.\mathrm{O}-\mathbf{C H}_{\mathbf{2}}-\mathrm{POSS}\right), 3.73\left(\mathrm{P}-\mathrm{O}-\mathbf{C H}_{\mathbf{3}}\right), 4.34$ $\left(\mathrm{O}-\mathbf{C H}_{2}-\mathrm{P}\right) . \quad{ }^{31} \mathrm{P} \quad \mathrm{NMR} \quad\left(\mathrm{DMSO}-d_{6}, \quad \delta, \quad \mathrm{ppm}\right): \quad 21.55$ $\left(\mathrm{CH}_{2}-\mathrm{P}(\mathrm{O})\left(\mathrm{OCH}_{3}\right)_{2}\right)$. SEC: $M_{\mathrm{n}}=7500 \mathrm{~g} \mathrm{~mol}^{-1}, M_{\mathrm{W}} / M_{\mathrm{n}}=1.9$.

The name and chemical composition of all materials are summarized in Table 1 .

Thermogravimetric analysis (TGA) was carried out on a Perkin Elmer Pyris- 1 instrument. The temperature range was varied from $50{ }^{\circ} \mathrm{C}$ to $900{ }^{\circ} \mathrm{C}$ at a heating rate of $10{ }^{\circ} \mathrm{C} \mathrm{min}^{-1}$ under nitrogen and air atmospheres. Specimen weighed $10 \mathrm{mg} \pm 2 \mathrm{mg}$. This TGA instrument was coupled to a Fourier transform infrared spectrometer (FT-IR) (Bruker-IFS66) to analyze the evolved gases (The heating rate and temperature range are identical to a simple TGA analysis.). FT-IR measurements were carried out in the range of $4000-400 \mathrm{~cm}^{-1}$, with 8 scans and spectral resolution of $1 \mathrm{~cm}^{-1}$. Flammability results were obtained from Pyrolysis Combustion Flow Calorimeter (PCFC) instrument (FTT Company) (specimen size $\sim 2-4 \mathrm{mg}$, heating rate $=1 \mathrm{~K} \mathrm{~s}^{-1}$, range of temperature from $100{ }^{\circ} \mathrm{C}$ to $750{ }^{\circ} \mathrm{C}$ ). The total heat release (THR) and heat release capacity (HRC) values were obtained from this test with an experimental error of 5\% [18] (sumHRC is the sum of all peaks of heat release rate after deconvolution carried out with the FTT software.). All images were obtained using a Scanning Electron Microscopy (FEI Quanta 200 SEM) under high vacuum at a voltage of $15.0 \mathrm{kV}$ with a spot size of $2.8 \mathrm{~mm}$ and a working distance of $8.2 \mathrm{~mm}$. The evolved gases during thermal degradation were analyzed using Pyrolyzer-GC/MS analysis. A Pyroprobe 5000 pyrolyzer (CDS Analytical) was used to flash pyrolyze the samples in a helium environment. This pyrolyzer is supplied with an electrically heated platinum filament. The sample (less than $1 \mathrm{mg}$ ) placed in a quartz tube between two pieces of rockwool. The same sample was heated at $400{ }^{\circ} \mathrm{C}$. This

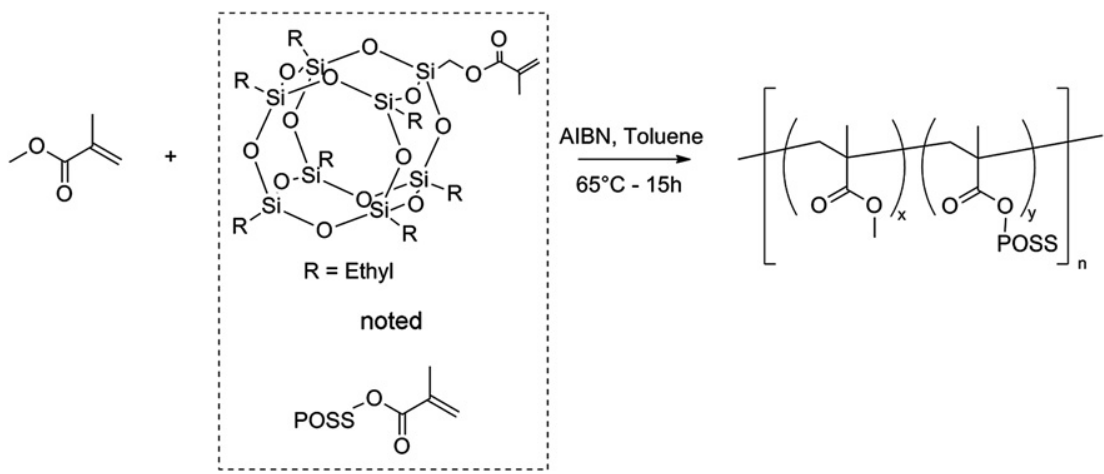

Scheme 2. Copolymerization of MMA with MA.POSS ( $x=0.9, y=0.1)$. 


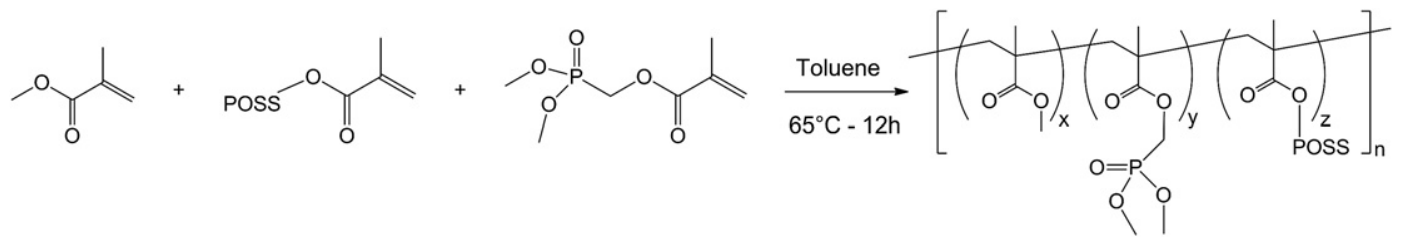

Scheme 3. Terpolymerization of MMA with MAPC1 and MA.POSS $(x=0.45, y=0.45, z=0.1)$.

temperature was selected according to the TGA curve. The pyroprobe 5000 is interfaced to a $450-G C$ gas chromatograph (Varian) by means of a chamber heated at $270{ }^{\circ} \mathrm{C}$. In the oven the initial temperature of $70^{\circ} \mathrm{C}$ was held for $5 \mathrm{~min}$, and then raised to $250{ }^{\circ} \mathrm{C}$ at $10{ }^{\circ} \mathrm{C} \mathrm{min}^{-1}$. A Varian Vf-5ms capillary column $(30 \mathrm{~m} \times 25 \mathrm{~mm})$ and helium $\left(1 \mathrm{~mL} \mathrm{~min}^{-1}\right)$ was used as the carrier gas, a split ratio was set to 1:50. The gases were introduced from the GC transfer line to the ion trap analyzer of the 240-MS mass spectrometer (Varian) through the direct-coupled capillary column. Identification of the products was achieved comparing the observed mass spectra to those of the NIST mass spectral library. ${ }^{1} \mathrm{H}$ and ${ }^{31} \mathrm{P}$ NMR spectra were recorded in deuterium solution (using 5-10 mg of each compound dissolved in $0.6 \mathrm{ml}$ of solvent) on a Bruker Avance $400 \mathrm{MHz}$ spectrometer. ${ }^{1} \mathrm{H}$ and ${ }^{31} \mathrm{P}$ chemical shifts are expressed in $\mathrm{ppm} / \mathrm{TMS}$ and $\mathrm{ppm} / \mathrm{H}_{3} \mathrm{PO}_{4}$. Molecular weight distributions were analyzed by gel permeation chromatography (GPC) using a Varian Q50 GPC with a differential refractive index detector and a column set consisting of two PL gel MixC. Tetrahydrofuran was used as eluent at $1.0 \mathrm{~mL} \mathrm{~min}{ }^{-1}$. Calibration of the GPC equipment was carried out with narrow polystyrene standards (Varian Standards, peak molecular weight range $162-1,238,000 \mathrm{~g} \mathrm{~mol}^{-1}$ ).

\section{Results and discussion}

\subsection{Physical incorporation of POSS into PMMA and copo.(MMA-MAPC1)}

\subsubsection{SEM analysis}

SEM images of PMMA/MA.POSS, PMMA/Tr.POSS, copo. (MMA-MAPC1)/MA.POSS and copo.(MMA-MAPC1)/Tr.POSS are

Table 1

Name and chemical composition of all materials (the slash (/) means "a physical blend").

\begin{tabular}{|c|c|c|}
\hline Sample & Abbreviated & $\begin{array}{l}\text { Preparation } \\
\text { method }\end{array}$ \\
\hline $\begin{array}{l}\text { Trisilanolphenyl-POSS } \\
\quad \text { (SO1458) }\end{array}$ & Tr.POSS & - \\
\hline $\begin{array}{l}\text { Methacrylateethyl-POSS } \\
\quad \text { (MA0716) }\end{array}$ & MA.POSS & - \\
\hline PMMA & PMMA & $\begin{array}{l}\text { Radical } \\
\text { polymerization }\end{array}$ \\
\hline $\begin{array}{l}\text { Dimethyl(methacryloyloxy) } \\
\text { methyl phosphonate }\end{array}$ & MAPC1 & Synthesis [5] \\
\hline PMMA/MA.POSS $10 w t . \%$ & PMMA/MA.POSS & $\begin{array}{l}\text { Solution casting } \\
\text { method }\end{array}$ \\
\hline PMMA/Tr.POSS ${ }_{10 w t . \%}$ & PMMA/Tr.POSS & $\begin{array}{l}\text { Solution casting } \\
\text { method }\end{array}$ \\
\hline $\begin{array}{l}\text { Copolymer } \\
\left.\text { (MMA }_{50 w t . \%-M A P C 1} 1_{50 w t . \%)}\right)\end{array}$ & Сopo.(MMA-MAPC1) & $\begin{array}{l}\text { Radical co- } \\
\text { polymerization }\end{array}$ \\
\hline $\begin{array}{l}\text { Copolymer (MMA-MAPC1)/ } \\
\text { MA.POSS } \\
10 w t . \%\end{array}$ & $\begin{array}{l}\text { Copo.(MMA-MAPC1)/ } \\
\text { MA.POSS }\end{array}$ & $\begin{array}{l}\text { Solution casting } \\
\text { method }\end{array}$ \\
\hline $\begin{array}{l}\text { Copolymer (MMA-MAPC1)/ } \\
\text { Tr.POSS } \\
10 \mathrm{wt} . \%\end{array}$ & $\begin{array}{l}\text { Copo.(MMA-MAPC1)/ } \\
\text { Tr.POSS }\end{array}$ & $\begin{array}{l}\text { Solution casting } \\
\text { method }\end{array}$ \\
\hline $\begin{array}{l}\text { Copolymer } \\
\left.\text { (MMA }_{90 w t . \%-M A . P O S S}{ }_{10 w t . \%}\right)\end{array}$ & Сopo.(MMA-MA.POSS) & $\begin{array}{l}\text { Radical co- } \\
\text { polymerization }\end{array}$ \\
\hline $\begin{array}{l}\text { Terpolymer } \\
\quad \text { (MMA }_{45 w t . \%-M A P C 1} 1_{45 w t . \%}- \\
\left.\text { MA.POSS }_{10 w t . \%}\right)\end{array}$ & $\begin{array}{l}\text { Terpo.(MMA-MAPC1- } \\
\text { MA.POSS) }\end{array}$ & $\begin{array}{l}\text { Radical ter- } \\
\text { polymerization }\end{array}$ \\
\hline
\end{tabular}

shown in Fig. 1. Spherically agglomerated morphologies can be observed using both types of POSS. In the case of Tr.POSS, the size of agglomerated particles is between 1 and $2 \mu \mathrm{m}$ in PMMA (Fig. 1b). The size of MA.POSS particles in PMMA is between $500 \mathrm{~nm}$ and $1 \mu \mathrm{m}$ and a better dispersion state was obtained with this type of POSS (Fig. 1a).

The blends of copo.(MMA-MAPC1) with MA.POSS or Tr.POSS present poorly dispersed morphologies compared to those of PMMA blends (Fig. 1c,d). In the copo.(MMA-MAPC1), both POSS exhibit a similar dispersion state despite the presence of the methacrylate group on MA.POSS. Hence, MA.POSS particles seem more compatible with PMMA than with copo.(MMA-MAPC1).

\subsubsection{Thermogravimetric analysis (TGA)}

Fig. 2 shows TGA and DTG analysis of PMMA and copolymer with MA.POSS or Tr.POSS. PMMA degrades in two steps $\left(290^{\circ} \mathrm{C}\right.$ and $390{ }^{\circ} \mathrm{C}$, maximum of the DTG curve peaks). According to other authors [19-22], the steps of degradation of PMMA correspond to the different types of polymer chains obtained from radical polymerization. The first step of degradation (around $290{ }^{\circ} \mathrm{C}$ ) takes place by scissions at the unsaturated chain ends (resulting from termination by disproportionation) involving homolytic $\beta$ scission of the vinyl group. The second step (around $390{ }^{\circ} \mathrm{C}$ ) is a random scission within the polymer chain [5]. PMMA/MA.POSS degrades in three steps $\left(186{ }^{\circ} \mathrm{C}, 290{ }^{\circ} \mathrm{C}\right.$ and $\left.390{ }^{\circ} \mathrm{C}\right)$. It seems that addition of POSS does not change the PMMA degradation pathway, since the first step of PMMA/MA.POSS could be attributed to degradation of MA.POSS only (Fig. 4a, b). PMMA/Tr.POSS degrades in two steps as PMMA and presents a better thermal stability over the whole temperature range than PMMA and PMMA/MA.POSS samples. The residue amounts are around 6\% for PMMA/Tr.POSS blends (at $700{ }^{\circ} \mathrm{C}$ ), $0 \%$ for PMMA and about $1 \%$ for PMMA/MA.POSS. The residue seems to consist essentially of silica from degraded POSS.

Copo.(MMA-MAPC1) and copo.(MMA-MAPC1)/Tr.POSS samples degrade in two steps $\left(330{ }^{\circ} \mathrm{C}\right.$ and $417{ }^{\circ} \mathrm{C}$ ) (Fig. 2d). The copolymer blended with MA.POSS degrades in three steps $\left(190^{\circ} \mathrm{C}\right.$, $344{ }^{\circ} \mathrm{C}$ and $\left.417{ }^{\circ} \mathrm{C}\right)$. The onset degradation temperatures of this sample (copo.(MMA-MAPC1)/MA.POSS) are decreased compared to pure copolymer. However, the copo.(MMA-MAPC1)/MA.POSS blend presents a better thermal stability than pure copolymer after $320^{\circ} \mathrm{C}$. In the case of copo.(MMA-MAPC1)/Tr.POSS, a better thermal stability is observed all over the analysis. The residue contents are around 23\%, 26\% and 30\% for copo.(MMA-MAPC1), copo.(MMA-MAPC1)/MA.POSS and copo.(MMA-MAPC1)/Tr.POSS, respectively. DTG curves reveal that only copo.(MMA-MAPC1)/ MA.POSS sample could present a different degradation pathway. It has been suggested in the literature that a non-interacting behavior between the components results in a linear combination of the TGA curves of the individual components $[23,24]$. In order to scrutinize this interaction, theoretical TGA curve obtained by linear combination of the TGA curves of MA.POSS or Tr.POSS has been computed (Fig. 3).

The comparison of theoretical (calculated) and experimental TGA curves shows that in the case of copo.(MMA-MAPC1)/ MA.POSS, the experimental curve presents a higher thermal 

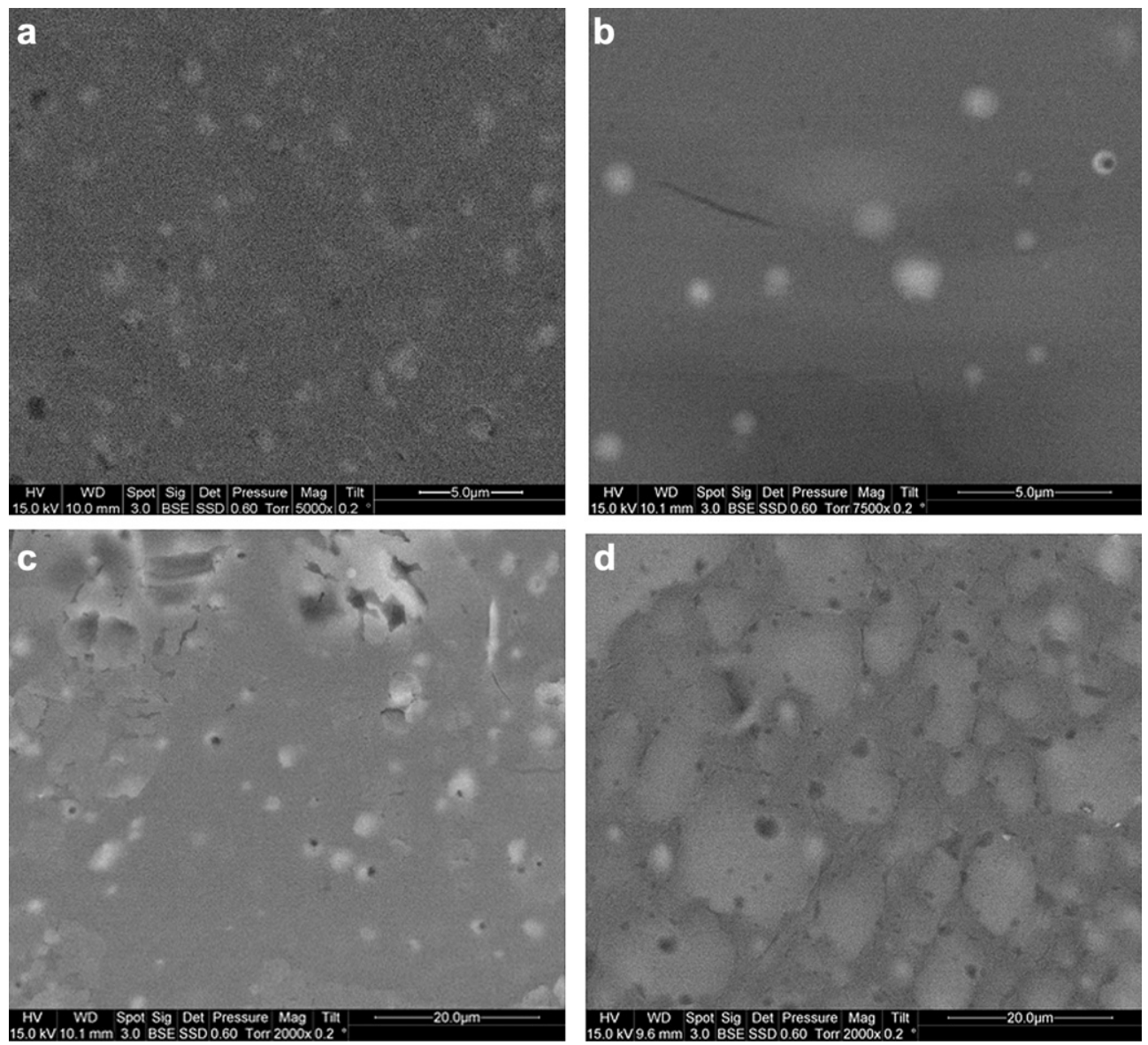

Fig. 1. SEM images of a) PMMA/MA.POSS, b) PMMA/Tr.POSS, c) copo.(MMA-MAPC1)/MA.POSS, d) copo.(MMA-MAPC1)/Tr.POSS
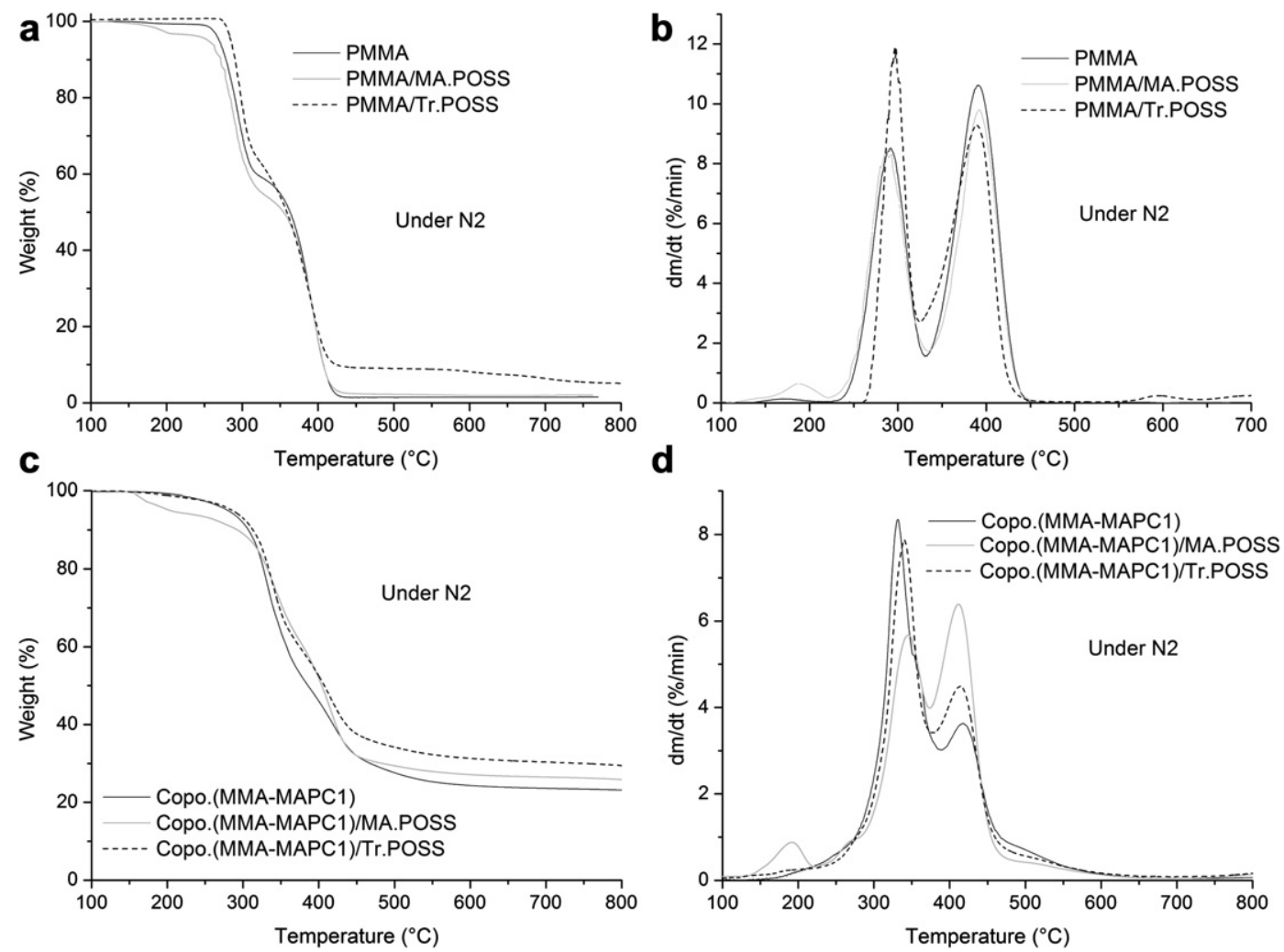

Fig. 2. TGA and DTG curves of pure PMMA and copo.(MMA-MAPC1) blend with MA.POSS and Tr.POSS at a heating rate of $10^{\circ} \mathrm{C} \min ^{-1}$ under nitrogen. 

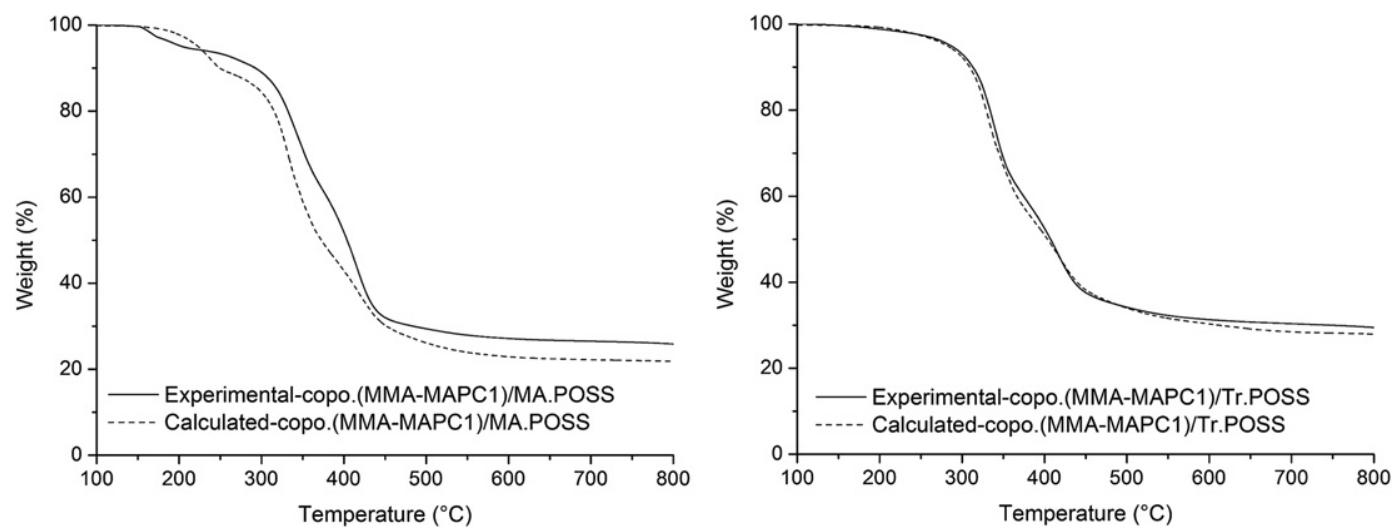

Fig. 3. Comparison of theoretical and experimental TGA curves of copo.(MMA-MAPC1)/MA.POSS and copo.(MMA-MAPC1)/Tr.POSS.

stability after $230{ }^{\circ} \mathrm{C}$ than the calculated curve. In other words, an interaction is evidenced between copo.(MMA-MAPC1) and MA.POSS. In the case of Tr.POSS, experimental and calculated TGA curves are well superposed, indicating a non-interacting behavior.

It appears that this difference is directly related to the nature and the different degradation pathway of both POSS. The thermal degradation of Tr.POSS occurs in two steps (Fig. 4 around $246{ }^{\circ} \mathrm{C}$ and $616{ }^{\circ} \mathrm{C}$ ). The first step corresponds to the loss of water molecules from the condensation reactions between silanols functions of POSS molecules. The hypothesis is that two Tr.POSS molecules contain six silanols groups which can give after condensation three water molecules. The weight loss of this first step of degradation (3 wt.\%) is in accordance with a loss of water molecules formed by silanols condensation (2.9 wt.\%). The second step of degradation corresponds to release of phenyl groups [10]. The residue content is constant after $700{ }^{\circ} \mathrm{C}$ (around $70 \mathrm{wt} . \%$ ).

The weight loss of MA-POSS, in TGA, takes place in two steps. The first step ( $80 \%$ weight loss) begins at $165^{\circ} \mathrm{C}$ (maximum of DTG peak at $250^{\circ} \mathrm{C}$ ). The second step begins around $300^{\circ} \mathrm{C}$ and presents $10 \%$ of weight loss. The obtained residue is around $10 \%$ after $600{ }^{\circ} \mathrm{C}$. It seems that the first step corresponds to the degradation of ethyl and methacrylate groups and the second step concerns the partial degradation of the POSS cage (Scheme 4). Fig. 2a indicates that the first step of MA.POSS degradation occurs at a lower temperature when incorporated in PMMA. The obtained POSS at this stage can act as radical trap which can react with radicals derived from degradation of copolymer to form more stable products [25]. These reactions occur near $320^{\circ} \mathrm{C}$.
In the case of Tr.POSS, the release of phenyl groups occurs at high temperature [17]. Therefore the silicon radical sites are not available when radicals obtained by degradation of the copolymer are formed, as described for MA.POSS.

\subsubsection{Pyrolysis-combustion flow calorimeter (PCFC)}

Fig. 5 displays PCFC curves of PMMA and copo.(MMA-MAPC1) with MA.POSS or Tr.POSS. These results are summarized in Table 1 . HRC is a parameter representative of polymer flammability. When a polymer decomposes in several steps, sumHRC must be considered. Both PMMA/MA.POSS and PMMA/Tr.POSS blends present two HRR peaks, similarly to PMMA.

sumHRC values are $345 \mathrm{~J} \mathrm{~g}^{-1} \mathrm{~K}^{-1}$ and $414 \mathrm{~J} \mathrm{~g}^{-1} \mathrm{~K}^{-1}$ for PMMA/ MA.POSS and PMMA/Tr.POSS blends, respectively (Table 2). Therefore, the decrease of sumHRC values is respectively around $21 \%$ and $5 \%$ compared to PMMA (438 $\mathrm{J} \mathrm{g}^{-1} \mathrm{~K}^{-1}$ ). In the case of PMMA/MA.POSS, the decrease of sumHRC is higher than that expected from the residue increase. This can be explained by the interaction between the products which formed from degradation of MA.POSS and PMMA. For PMMA/Tr.POSS sample, these interactions do not occur since the degradation of Tr-POSS occurs within a temperature range much higher than that of PMMA.

A slight decrease of THR values are also observed for both blends compared to pure PMMA.

The incorporation of both POSS into copo.(MMA-MAPC1) leads to increase the sumHRC values $\left(207 \mathrm{~J} \mathrm{~g}^{-1} \mathrm{~K}^{-1}\right.$ and $249 \mathrm{~J} \mathrm{~g}^{-1} \mathrm{~K}^{-1}$ respectively for copo.(MMA-MAPC1)/MA.POSS and copo.(MMA-MAPC1)/Tr.POSS compared to PMMA). A slight
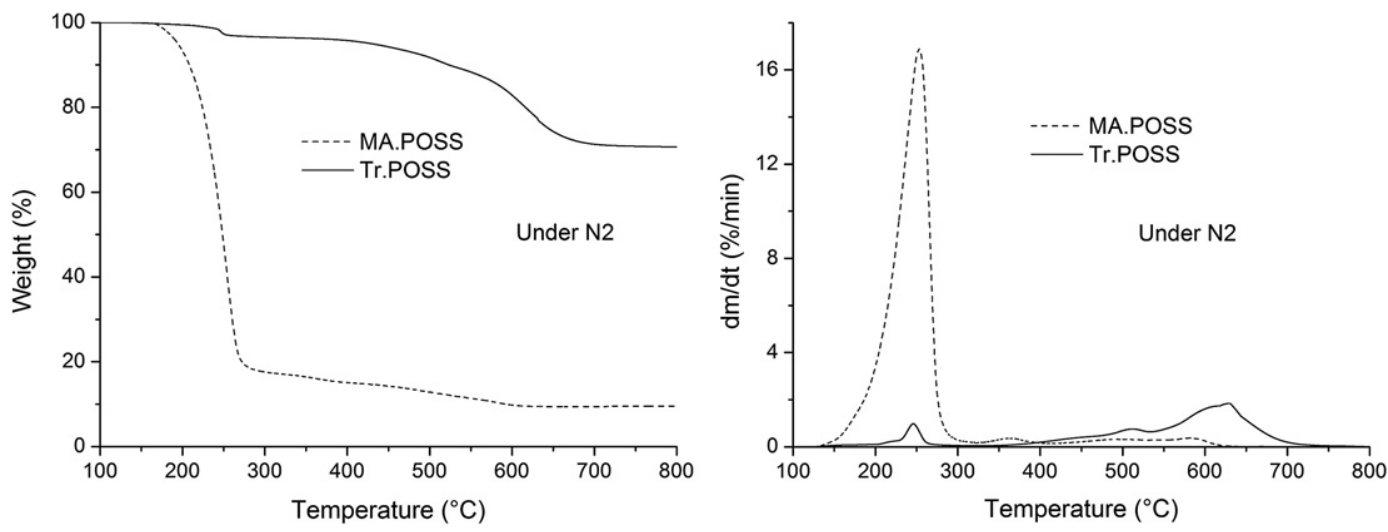

Fig. 4. TGA and DTG curves of MA.POSS and Tr.POSS at a heating rate of $10{ }^{\circ} \mathrm{C} \min ^{-1}$ under nitrogen. 


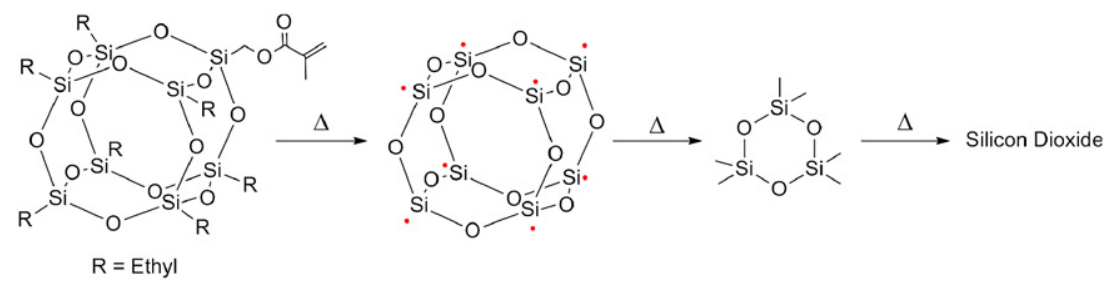

Scheme 4. Mechanism of thermal degradation of MA.POSS.
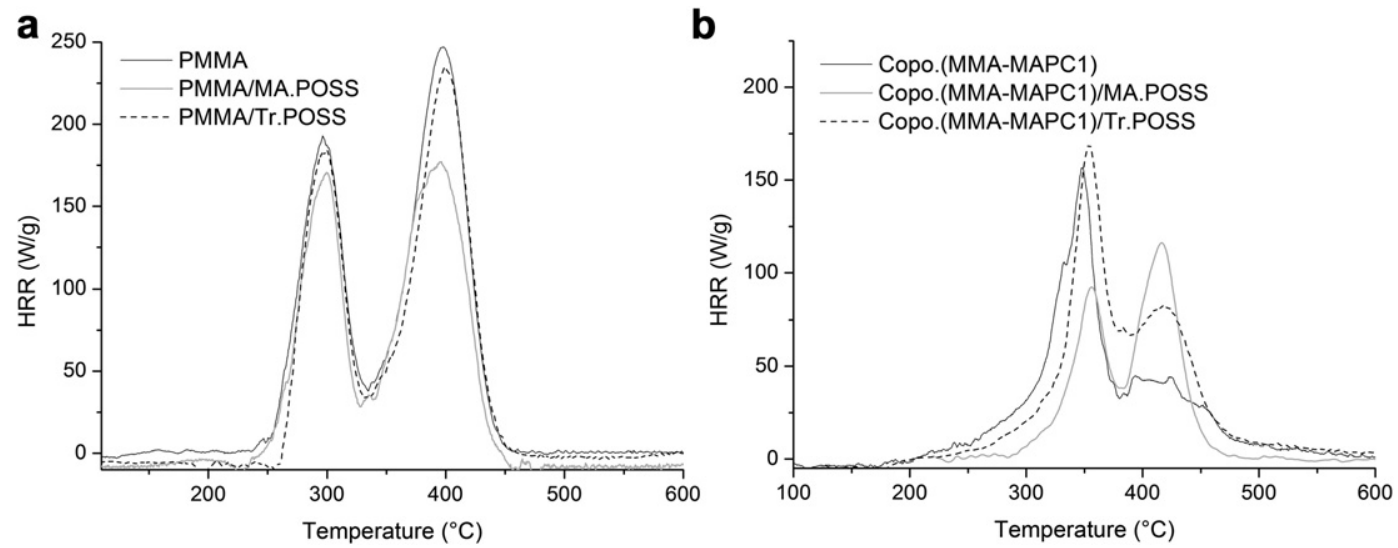

Fig. 5. HRR curves of PMMA a), and copo.(MMA-MAPC1) b) with MA.POSS or Tr.POSS.

decrease of THR is observed for copo.(MMA-MAPC1)/MA.POSS. In the case of copo.(MMA-MAPC1)/Tr.POSS, THR values increased compared to that of copo.(MMA-MAPC1).

HRR curve reveals that copo.(MMA-MAPC1)/MA.POSS presents a different degradation pathway compared to copo.(MMA-MAPC1)/Tr.POSS. As can be seen from Fig. 5b, the first step of heat release is similar for copo.(MMA-MAPC1) and copo.(MMA-MAPC1)/Tr.POSS. Conversely, in the case of copo.(MMA-MAPC1)/MA.POSS, a remarkable decrease of the first HRR peak is observed whereas the second peak is enhanced. The decrease of HRR peak can be explained by the reaction between the evolved phosphorus products obtained by degradation of copo.(MMA-MAPC1) and silicon radical sites obtained by degradation of MA.POSS (Scheme 5). These reactions can lead to more stable POSS species and thus lower HRR values within this range of temperature.

This hypothesis is in accordance with the release of phosphorus species observed between $325{ }^{\circ} \mathrm{C}$ and $425{ }^{\circ} \mathrm{C}$, as proved by the Gram-Schmidt curve of $\mathrm{P}-\mathrm{O}-\mathrm{C}$ band $\left(1026 \mathrm{~cm}^{-1}\right)$ obtained from TGA coupled FT-IR analysis of copo.(MMA-MAPC1) (Fig. 6).

These results have been confirmed using Py-GC/MS analysis. Fig. 7a shows the chromatogram generated from the analysis of copo.(MMA-MAPC1) and copo.(MMA-MAPC1)/MA.POSS samples at $400{ }^{\circ} \mathrm{C}$. The common peaks are identified in Fig. 7b.

The GC chromatograms were used to evaluate the difference between the two samples. For each chromatogram the areas of the different peaks have been measured and divided by the area value of the reference peak corresponding to MMA (peak $\mathbf{\Delta}$ ). It should be noted that with the exception of MMA, the other observed peaks correspond to phosphorus products (retention time $=5.38,6.51$, 7.3, 9.5, 14.09 and $17.7 \mathrm{~min}$ ). The main results are summarized in Table 3. It may be supposed that the absence of the reaction between copo.(MMA-MAPC1) and MA.POSS could lead to similar peaks ratios for copo.(MMA-MAPC1) and copo.(MMA-MAPC1)/ MA.POSS samples. Nevertheless, the results show that all the ratios (except one) are lower in the case of copo.(MMA-MAPC1)/ MA.POSS what correspond to a decrease of phosphorus products formation during the pyrolysis phase. The Py-GC/MS analysis seems to confirm the hypothesis of reaction between phosphorus products obtained by degradation of copo.(MMA-MAPC1) and the silicon radical sites obtained by degradation of MA.POSS.

It can be concluded that the physical incorporation of Tr.POSS into PMMA or copo.(MMA-MAPC1) improves thermal stability, which is not the case with MA-POSS. However, PMMA/MA.POSS presents a better HRC value than PMMA/Tr.POSS. For copo.(MMA-MAPC1) blends, a better flammability behavior is observed with MA.POSS. In all cases, blends of PMMA or copo.(MMA-MAPC1) with Tr.POSS or MA.POSS, it is difficult to obtain a homogeneous dispersion of POSS molecules on a molecular scale (1-3 nm). This observation led us to use a new strategy based on the incorporation of the POSS cage in the polymer via a copolymerization method.

\subsection{Chemical incorporation of POSS into PMMA (copo.(MMA-MA.POSS))}

\subsubsection{Thermogravimetric analysis (TGA)}

MA.POSS has been chemically incorporated (10 wt.\%) into PMMA via a radical copolymerization and named as

\section{Table 2}

Summary results of PCFC tests for PMMA and copo.(MMA-MAPC1) with MA.POSS or Tr.POSS.

\begin{tabular}{lll}
\hline & sumHRC $\left(\mathrm{J} \mathrm{g}^{-1} \mathrm{~K}^{-1}\right)$ & $\mathrm{THR}\left(\mathrm{kJ} \mathrm{g}^{-1}\right)$ \\
\hline PMMA & 438 & 23 \\
PMMA/MA.POSS & 345 & 20 \\
PMMA/Tr.POSS & 414 & 22 \\
Copo.(MMA-MAPC1) & 200 & 12 \\
Copo.(MMA-MAPC1)/MA.POSS & 207 & 11 \\
Copo.(MMA-MAPC1)/Tr.POSS & 249 & 16 \\
\hline
\end{tabular}




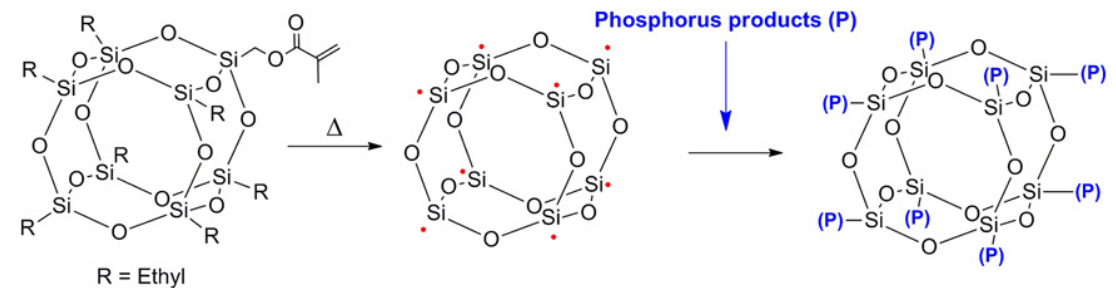

Scheme 5. Reactions between POSS silicon radical sites and phosphorus compounds released from copo.(MMA-MAPC1).

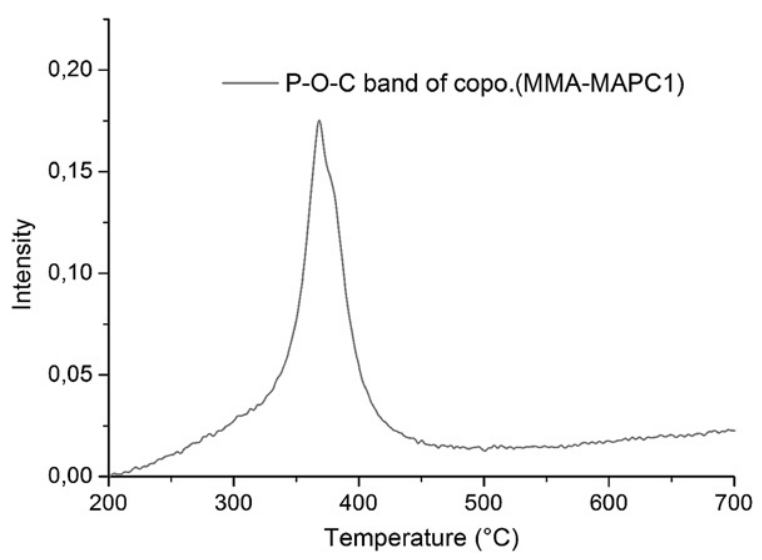

Fig. 6. Gram-Schmidt curve, as a function of temperature, for $\mathrm{P}-\mathrm{O}-\mathrm{C}$ band of copo.(MMA-MAPC1) obtained from TGA-coupled FT-IR analysis (under $\mathrm{N}_{2}$, $\left.10{ }^{\circ} \mathrm{C} \min ^{-1}\right)$.

copo.(MMA-MA.POSS) (as described in Materials and methods part). This copolymer is compared to physical blend of PMMA/ MA.POSS (10 wt.\%) in term of thermal stability and flammability properties.

Fig. 8 displays the TGA and DTG curves of chemically and physically incorporated POSS into PMMA. The copo.(MMA-MA.POSS) exhibits three steps of degradation (at $220^{\circ} \mathrm{C}, 300^{\circ} \mathrm{C}$ and $365^{\circ} \mathrm{C}$ ). A higher residue percentage ( $\left.\sim 8 \mathrm{wt} . \%\right)$ and a better thermal stability (except between $345^{\circ} \mathrm{C}$ and $400^{\circ} \mathrm{C}$ ) is observed for this sample compared to the PMMA/MA.POSS sample.

The chemical incorporation of POSS into PMMA induces a change of weight loss curve. As for PMMA, we suppose that the three steps of degradation of the copolymer in TGA could correspond to the possible three types of chains that can be generated from termination reactions during the polymerization (Scheme 6).
Table 3

Summary results of Py-GC/MS analysis of copo.(MMA-MAPC1) and copo.(MMA-MAPC1)/MA.POSS samples.

\begin{tabular}{|c|c|c|c|}
\hline & \multirow{2}{*}{$\begin{array}{l}\text { Retention } \\
\text { time (min) }\end{array}$} & \multicolumn{2}{|c|}{ (Area value peak)/(area value of peak $\boldsymbol{\Delta}$ ) } \\
\hline & & Copo.(MMA-MAPC1) & $\begin{array}{l}\text { Copo.(MMA-MAPC1)/ } \\
\text { MA.POSS }\end{array}$ \\
\hline$\Delta$ & 4.18 & 1 & 1 \\
\hline$\imath / \mathbf{A}$ & 5.38 & 2.32 & 1.6 \\
\hline $\mathrm{O} / \mathbf{\Delta}$ & 6.51 & 2.25 & 1.64 \\
\hline$\triangle / \Delta$ & 7.3 & 1.03 & $2.8 \times 10^{-4}$ \\
\hline$\star / \mathbf{\Delta}$ & 9.5 & 2.6 & 1.05 \\
\hline O/A & 14.09 & 1.83 & 2.7 \\
\hline O/A & 17.7 & 3.3 & 3.4 \\
\hline
\end{tabular}

The first step of degradation $\left(220^{\circ} \mathrm{C}\right)$ could correspond to the degradation of the chain issue from recombination (Scheme 6a). The second step of degradation $\left(300^{\circ} \mathrm{C}\right)$ corresponds to the chains obtained by disproportionation (Scheme 6.b and c). Finally, the third step of degradation $\left(365^{\circ} \mathrm{C}\right)$ corresponds to a random scission within the polymer chain.

\subsubsection{Pyrolysis-combustion flow calorimeter (PCFC)}

Fig. 9 presents the HRR curves of copo.(MMA-MA.POSS) and PMMA/MA.POSS samples. These results are summarized in Table 4 (sumHRC and THR values). Copo.(MMA-MA.POSS) presents three peaks of HRR instead of two peaks for PMMA/MA.POSS. The comparison of sumHRC and THR values shows a difference between these samples in terms of flammability. Chemical incorporation of
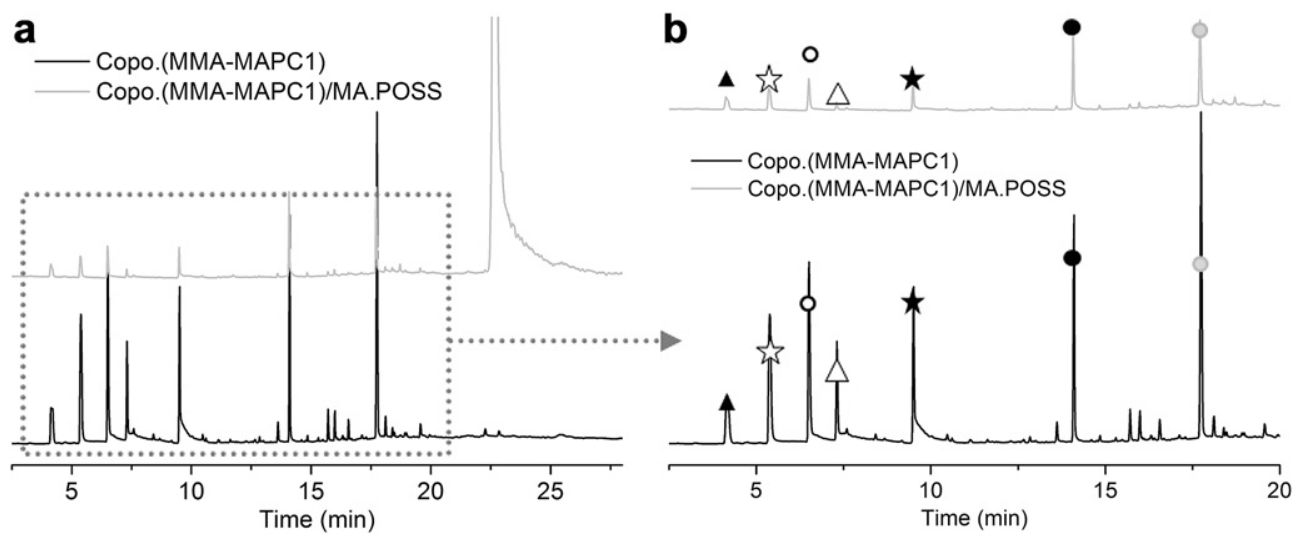

Fig. 7. Py-GC/MS analysis of copo.(MMA-MAPC1) and copo.(MMA-MAPC1)/MA.POSS samples. 

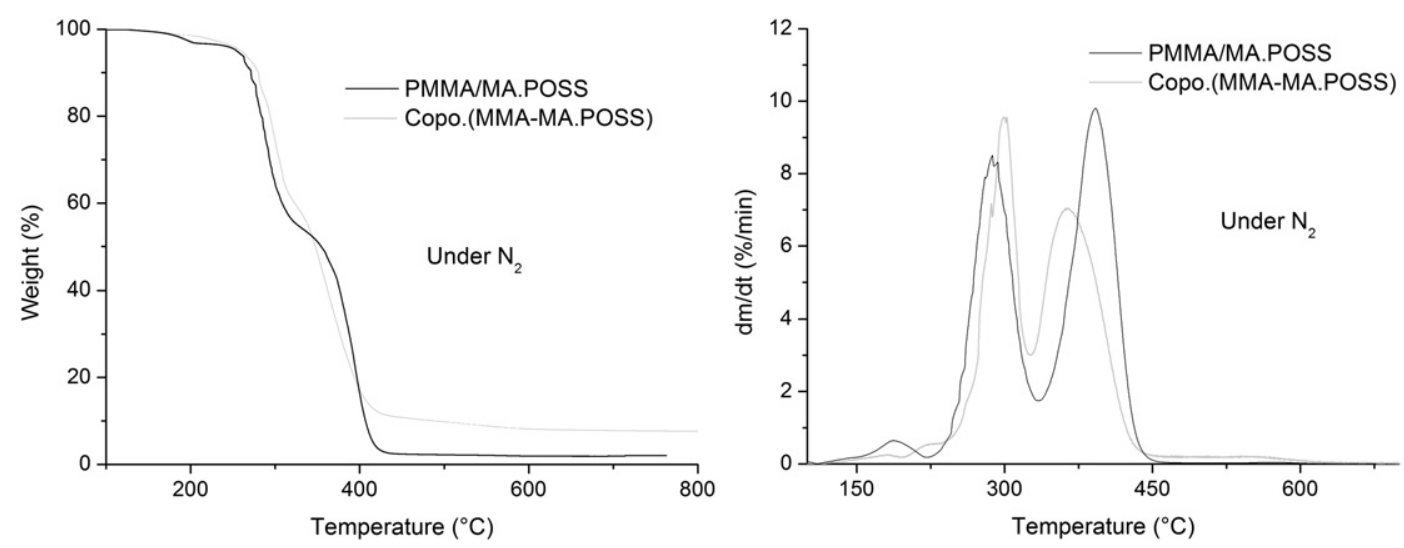

Fig. 8. TGA and DTG curves of PMMA/MA.POSS and copo.(MMA-MA.POSS) samples at a heating rate of $10^{\circ} \mathrm{C}$ min $^{-1}$ under nitrogen.

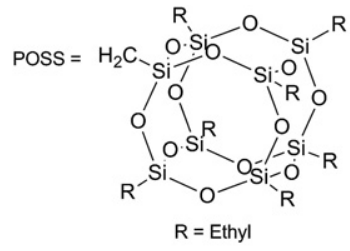<smiles>COC(=O)/C(C)=C\C(C)(C)C(C)(CC(C)(C)C(C)(C)C(C)(C)C(=O)O[18O])C(=O)OC</smiles>

(b)

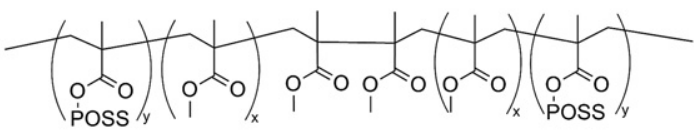

(a) $x>>y$

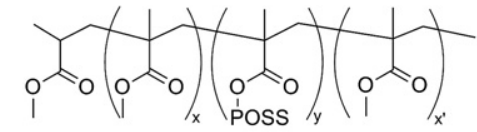

(c)

Scheme 6. Three types of chain structure from radical copolymerization of MMA and MA.POSS.

POSS into PMMA offers better results (lower sumHRC and THR) than physical incorporation.

\subsection{Chemical incorporation of POSS into phosphonated modified PMMA (terpo.(MMA-MAPC1-MA.POSS))}

A terpolymer terpo.(MMA-MAPC1-MA.POSS) was synthesized as described in Materials and methods part. The quantity of MA.POSS was fixed at $10 \mathrm{wt}$.\% in order to compare this terpolymer with a physical blend of copo.(MMA-MAPC1) and MA.POSS.

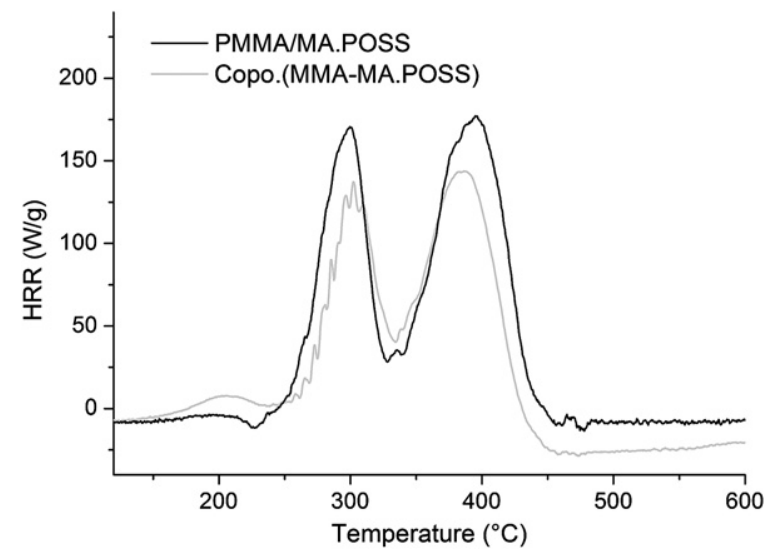

Fig. 9. HRR curves of PMMA/MA.POSS and copo.(MMA-MA.POSS) samples.

\subsubsection{Thermogravimetric analysis (TGA)}

The TGA and DTG curves of copo.(MMA-MAPC1), copo.(MMA-MAPC1)/MA.POSS and terpo.(MMA-MAPC1-MA.POSS) samples are presented in Fig. 10. The results of the 1st and 2nd samples were interpreted in part 3.2.1. Terpo.(MMA-MAPC1MA.POSS ) degrades in four steps $\left(220^{\circ} \mathrm{C}, 295^{\circ} \mathrm{C}, 400{ }^{\circ} \mathrm{C}, 600^{\circ} \mathrm{C}\right)$. The $T_{\text {onset }}$ of terpo.(MMA-MAPC1-MA.POSS) $\left(165^{\circ} \mathrm{C}\right)$ is higher than for copo.(MMA-MAPC1)/MA.POSS blend. However, copo.(MMA-MAPC1)/MA.POSS sample presents a better thermal stability than the terpolymer between $220{ }^{\circ} \mathrm{C}$ and $420{ }^{\circ} \mathrm{C}$. The residue amount is quasi- similar for both samples after $620{ }^{\circ} \mathrm{C}$ ( 25 wt.\%).

\subsubsection{Pyrolysis-combustion flow calorimeter (PCFC)}

Fig. 11 displays the HRR curves of these samples. sumHRC and THR values are reported in Table 5. Copo.(MMA-MAPC1)/ MA.POSS presents the better results (lower values for sumHRC and THR) compared to terpo.(MMA-MAPC1-MA.POSS). This difference can be explained in part by the reaction that we explained in part 3.1.3.

Table 4

Summary results of PCFC tests for pure PMMA/MA.POSS and copo.(MMA-MA.POSS).

\begin{tabular}{lll}
\hline & sumHRC $\left(\mathrm{J} \mathrm{g}^{-1} \mathrm{~K}^{-1}\right)$ & $\mathrm{THR}\left(\mathrm{kJ} \mathrm{g}^{-1}\right)$ \\
\hline PMMA/MA.POSS & 345 & 20 \\
Copo.(MMA-MA.POSS) & 298 & 17.9 \\
\hline
\end{tabular}



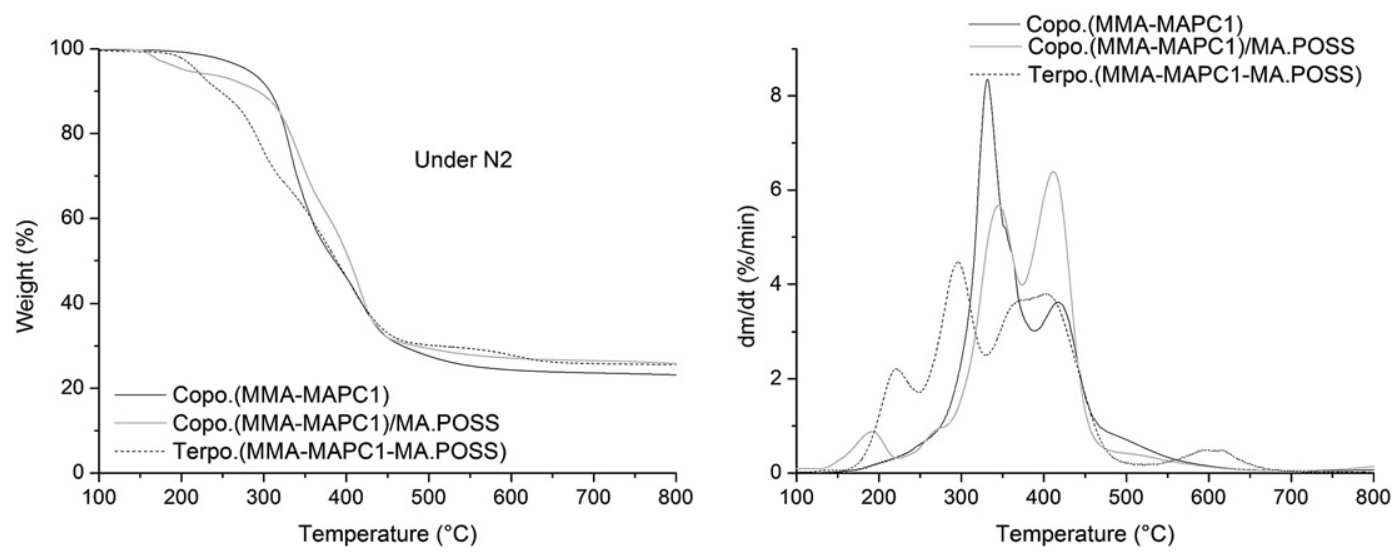

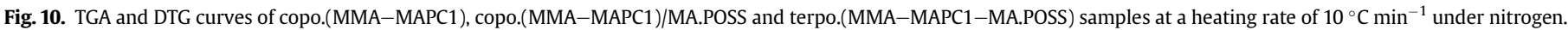

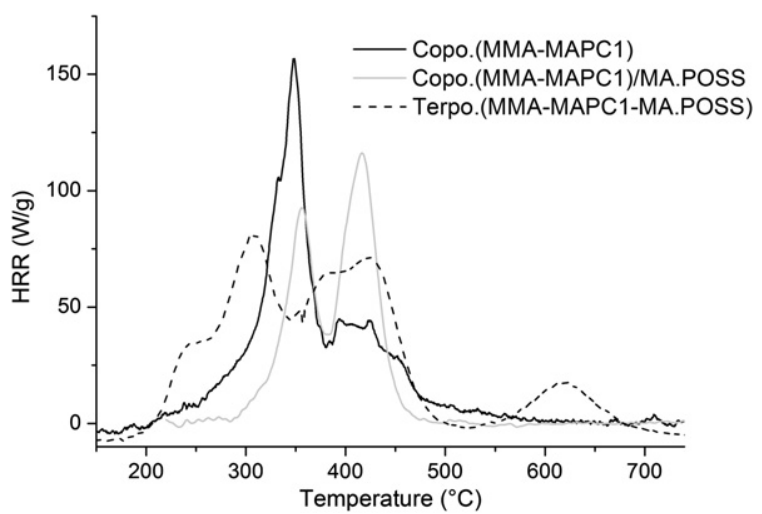

Fig. 11. HRR curves of copo.(MMA-MAPC1), copo.(MMA-MAPC1)/MA.POSS and terpo.(MMA-MAPC1-MA.POSS) samples.

Table 5

Summary results of PCFC tests for copo.(MMA-MAPC1), copo.(MMA-MAPC1)/ MA.POSS blend and terpo.(MMA-MAPC1--MA.POSS).

\begin{tabular}{lll}
\hline & $\operatorname{sumHRC}\left(\mathrm{J} \mathrm{g}^{-1} \mathrm{~K}^{-1}\right)$ & $\mathrm{THR}\left(\mathrm{kJ} \mathrm{g}^{-1}\right)$ \\
\hline Copo.(MMA-MAPC1) & 200 & 12 \\
Copo.(MMA-MAPC1)/MA.POSS & 207 & 11 \\
Terpo.(MMA-MAPC1-MA.POSS) & 218 & 17.4 \\
\hline
\end{tabular}

\section{Conclusion}

The thermal degradation and flammability behavior of PMMA and phosphonated PMMA in the presence of POSS molecules were investigated using TGA and PCFC analysis. TGA has shown a better thermal stability for PMMA and copo.(MMA-MAPC1) filled with Tr.POSS but the copo.(MMA-MAPC1)/MA.POSS blend presented a reduced flammability in PCFC test. This reduction was attributed to interactions between phosphorus compounds resulting from the degradation of copo.(MMA-MAPC1) and the silicon radical sites resulting from the degradation of MA.POSS. The chemical incorporation of MA.POSS into the PMMA chains via a copolymerization route leads to a greater improvement of thermal stability, residue amount and flammability properties than the physical incorporation. These promising results need to be confirmed at macroscopic scale. Indeed, additional actions, such as barrier effect, could be expected from POSS molecules during combustion. However this effect can only be evaluated by confronting PCFC and cone calorimeter tests.

\section{References}

[1] D. Price, K. Pyrah, T.R. Hull, G.J. Milnes, J.R. Ebdon, B.J. Hunt, P. Joseph, Polym. Degrad. Stab. 77 (2002) 227-233.

[2] A. Gentilhomme, M. Cochez, M. Ferriol, N. Oget, J.L. Mieloszynski, Polym. Degrad. Stab. 82 (2003) 347-355.

[3] J. Zhu, P. Start, K.A. Mauritz, C.A. Wilkie, Polym. Degrad. Stab. 77 (2002) $253-258$.

[4] A. Laachachi, E. Leroy, M. Cochez, M. Ferriol, J.M. Lopez Cuesta, Polym. Degrad. Stab. 89 (2005) 344-352.

[5] H. Vahabi, L. Ferry, C. Longuet, R. Sonnier, C. Negrell-Guirao, G. David, J.M. Lopez Cuesta, Eur. Polym. J. 48 (2012) 604-612.

[6] J.M. Lopez Cuesta, F. Laoutid, in: C.A. Wilkie, A.B. Morgan (Eds.), Fire Retardancy of Polymeric Materials, CRC Press, Inc., New York, 2009, pp. 301-328.

[7] L. Wang, S. Su, D. Chen, C.A. Wilkie, Polym. Degrad. Stab. 94 (2009) 1110-1118.

[8] D. Gnanasekaran, K. Madhavan, B.S.R. Rcddy, J. Sci. Ind. Res. 68 (2009) 437-464.

[9] X. Wang, L. Wu, J. Li, Adv. Polym. Technol. 30 (2011) 33-40.

[10] A. Fina, D. Tabuani, F. Carniato, A. Frache, E. Boccaleri, G. Camino, Thermochim. Acta 440 (2006) 36-42.

[11] I. Blanco, L. Abate, F.A. Bottino, P. Bottino, J. Therm. Anal. Calorim. 108 (2012) 807-815.

[12] L. Zheng, R.J. Farris, E.B. Coughlin, Macromolecules 34 (2001) 8034-8039.

[13] E.T. Kopesky, G.H. McKinley, R.E. Cohen, Polymer 46 (2005) 4743-4752.

[14] E.T. Kopesky, G.H. McKinley, R.E. Cohen, Polymer 47 (2006) 299-309.

[15] J.D. Lichtenhan, Y.A. Otonari, M.J. Carr, Macromolecules 28 (1995) 8435-8437.

[16] S. Bizet, J. Galy, J.F. Gérard, Macromolecules 39 (2006) 2574-2583.

[17] S. Bizet, J. Galy, J.F. Gérard, Polymer 47 (2006) 8219-8227.

[18] R.E. Lyon, R.N. Walters, J. Anal. Appl. Pyrolysis 71 (2004) 27-46.

[19] T. Kashiwagi, A. Inaba, J.E. Brown, K. Hatada, T. Kitayama, E. Masuda, Macromolecules 19 (1986) 2160-2168.

[20] L.E. Manring, D.Y. Sogah, G.M. Cohen, Macromolecules 22 (1989) 4652-4654.

[21] J.D. Peterson, S. Vyazovkin, C.A. Wight, Macromol. Rapid Commun. 20 (1999) 480-483.

[22] M. Ferriol, A. Gentilhomme, M. Cochez, N. Oget, J.L. Mieloszynski, Polym. Degrad. Stab. 79 (2003) 271-281.

[23] W. Xing, L. Song, H. Lu, Y. Hu, S. Zhou, Polym. Adv. Technol. 20 (2009) 696-702.

[24] K. Wu, M.M. Shen, Y. Hu, W. Xing, X. Wang, J. Therm. Anal. Calorim. 104 (2011) 1083-1090.

[25] X. Wang, Y. Hu, L. Song, W. Xing, H. Lu, J. Polym. Sci., Part B: Polym. Phys. 48 (2010) 693-705. 